Article

\title{
Hydrogen Sorption Kinetics of SiC-Coated Zr-1Nb Alloy
}

\author{
Egor B. Kashkarov ${ }^{1, *(\mathbb{D})}$, Maxim S. Syrtanov ${ }^{1}$, Tatyana L. Murashkina ${ }^{1}{ }^{(\mathbb{C},}$ \\ Alexander V. Kurochkin ${ }^{1}$, Yulia Shanenkova ${ }^{2}$ (i) and Aleksei Obrosov ${ }^{3}$ (i) \\ 1 School of Nuclear Science and Engineering, National Research Tomsk Polytechnic University, \\ 634050 Tomsk, Russian; maxim-syrtanov@mail.ru (M.S.S.); tatyanavolokitina@gmail.com (T.L.M.); \\ avkurochkin93@mail.ru (A.V.K.) \\ 2 School of Energy and Power Engineering, National Research Tomsk Polytechnic University, \\ 634050 Tomsk, Russian; julia_kolganova@mail.ru \\ 3 Department of Physical Metallurgy and Materials Technology, Brandenburg Technical University, \\ 03046 Cottbus, Germany; aleksei.obrosov@b-tu.de \\ * Correspondence: egor_kashkarov@mail.ru; Tel.: +7-952-802-0688
}

Received: 12 November 2018; Accepted: 3 January 2019; Published: 8 January 2019

\begin{abstract}
This paper describes the influence of silicon carbide ( $\mathrm{SiC}$ ) coating on hydrogen sorption kinetics of zirconium alloy E110 (Zr-1Nb). Amorphous SiC coating of 1.5- $\mu$ m thickness was deposited on $\mathrm{Zr}-1 \mathrm{Nb}$ alloy substrate by direct current magnetron sputtering of composite cathode. Hydrogen absorption by $\mathrm{SiC}$-coated $\mathrm{Zr}-1 \mathrm{Nb}$ alloy significantly decreased due to low hydrogen permeability of the coating. Hydrogenation tests show that $\mathrm{SiC}$ coating provides protective properties against hydrogen permeation in the investigated temperature range of $350-450{ }^{\circ} \mathrm{C}$. It was shown that hydrogenation of uncoated $\mathrm{Zr}-1 \mathrm{Nb}$ leads to formation of $\delta$ hydrides at $350{ }^{\circ} \mathrm{C}$ and $\delta$ and $\gamma$ hydrides at higher temperatures whereas in the SiC-coated $\mathrm{Zr}-1 \mathrm{Nb}$ alloy only $\delta$ hydrides formed. Gradient hydrogen distribution through the $\mathrm{SiC}$ coating and $\mathrm{H}$ trapping in the carbon-rich interface was observed. The adhesion strength of the coating was $\sim 5 \mathrm{~N}$. Hydrogenation up to $450{ }^{\circ} \mathrm{C}$ for $5 \mathrm{~h}$ does not degrade the adhesion properties during scratch testing.
\end{abstract}

Keywords: hydrogen sorption; hydrogenation; zirconium alloys; E110 (Zr-1Nb); SiC coating; magnetron sputtering; adhesion

\section{Introduction}

Zirconium alloys are used as materials for fuel cladding in the core of nuclear reactors due to low thermal neutron capture cross-section, high corrosion resistance and mechanical strength [1]. Despite a large number of Zr alloys such as Zirlo (USA) [2], M5 (France) and E-series (Russia) [3], which have been developed to improve their properties, especially corrosion resistance, the problems of high-temperature oxidation and hydrogenation of fuel claddings still remain. A common alloy used in Russia is E110 (Zr-1Nb), which is manufactured for fuel cladding of water-cooled nuclear reactors.

Hydrogen has an important role in the corrosion process of zirconium alloys during reactors operation. Hydrogen is generated as a result of water radiolysis and high temperature oxidation of zirconium alloys. Additionally, hydrogen can accumulate in the nuclear core from contact with other materials such as structural steels. Since the concentration of hydrogen in zirconium exceeds the solubility limit ( 150 ppm at $350{ }^{\circ} \mathrm{C}$ [4]) in the solid state, hydride precipitation occurs in the material cladding, which could lead to embrittlement [5-8]. Currently, various protective coatings such as $\mathrm{Al}_{2} \mathrm{O}_{3}$ [9], $\mathrm{ZrO}_{2}$ [10], $\mathrm{TiN}$ [11,12], $\mathrm{Cr}_{3} \mathrm{C}_{2}-\mathrm{NiCr}$ [13], and $\mathrm{SiC}$ [14] have been developed to improve oxidation resistance of $\mathrm{Zr}$ alloys and reduce hydrogen uptake. 
Silicon carbide is one of the main candidates to protect or replace zirconium fuel claddings due to higher melting temperature, better corrosion resistance at high temperatures and similar thermal neutron capture cross-section compared to zirconium [15]. Extensive research is being conducted on the $\mathrm{SiC}$ fabrication process and its material properties as a potential fuel cladding candidate $[16,17]$. Deposition of $\mathrm{SiC}$ coatings is also a promising way to improve corrosion resistance of $\mathrm{Zr}$ alloys [13]. It has been shown that $\mathrm{SiC}$ coatings demonstrate high hardness, high thermal conductivity and good oxidation resistance at high temperatures $[18,19]$. The mechanical properties of SiC coating deposited by magnetron sputtering on Zircaloy-4 substrate are investigated in [20], where the authors show that the hardness and elastic modulus of the deposited films decrease with increasing working pressure. Al-Olayyan et al. [21] have demonstrated the effect of SiC coating on oxidation resistance of Zircaloy-4. It was established that strong adhesion of $\mathrm{SiC}$ film on rough surfaces of Zircaloy-4 resulted in higher corrosion resistance. Usui et al. [13] have shown that the radio frequency (RF) magnetron sputtered $\mathrm{SiC}$ coatings demonstrate higher oxidation resistance when the coating was thicker, however their adhesion strength becomes lower. Thicker coatings could be vulnerable to cracking when temperature and pressure conditions change with time in a nuclear reactor. Moreover, decrease in hydrogen permeability due to $\mathrm{SiC}$ coating deposition on steel substrates has also been demonstrated. However, hydrogen permeation into SiC-coated zirconium alloy and its absorption has not been investigated, which makes it impossible to assess its protective properties against $\mathrm{H}$ penetration. Moreover, the hydrogen absorption kinetics of $\mathrm{Zr}-1 \mathrm{Nb}$ alloy with $\mathrm{SiC}$ protective coating have not been studied. It is important to establish the dependence of temperature on hydrogenation rate of SiC-coated zirconium alloys. Thus, the purpose of this work is to study the kinetics of hydrogen sorption by a $\mathrm{Zr}-1 \mathrm{Nb}$ alloy with $\mathrm{SiC}$ coating at various temperatures.

\section{Materials and Methods}

\subsection{Coating Deposition}

The SiC coating was deposited by direct current (DC) magnetron sputtering of $\mathrm{SiC}$ composite cathode. Zirconium alloy E110 (Zr-1Nb) having the dimensions $20 \mathrm{~mm} \times 20 \mathrm{~mm} \times 2 \mathrm{~mm}$ was used as a substrate. The composition of E110 alloy: $0.9-1.1 \mathrm{Nb}, 0.05 \mathrm{O}, 0.015 \mathrm{Fe}, 0.02 \mathrm{C}$, $\mathrm{Zr}$ balanced. The substrates were previously polished to the average roughness of $\mathrm{Ra} 0.05 \mu \mathrm{m}$ to remove surface oxides and organic contaminations. After polishing, the substrates were ultrasonically cleaned in acetone for $15 \mathrm{~min}$. The residual pressure in the vacuum chamber was $10^{-3} \mathrm{~Pa}$. Prior to deposition, the substrate surface was etched by Ar ions at following parameters: Ar working gas, voltage $1.5 \mathrm{kV}$, current $0.1 \mathrm{~A}$ and treatment time $20 \mathrm{~min}$. Then, $\mathrm{SiC}$ coating was deposited at the parameters presented in Table 1.

Table 1. Deposition parameters.

\begin{tabular}{cc}
\hline Parameter & Value \\
\hline Discharge power & $1000 \mathrm{~W}$ \\
Current & $1.47-1.48 \mathrm{~A}$ \\
Voltage & $527-532 \mathrm{~V}$ \\
Working pressure (Ar) & $0.12 \mathrm{~Pa}$ \\
Deposition time & $50 \mathrm{~min}$ \\
Distance to substrate & $100 \mathrm{~mm}$ \\
\hline
\end{tabular}

\subsection{Hydrogenation}

Hydrogenation of the samples was carried out in gas atmosphere using Gas Reaction Controller (Advanced Materials Corporation, Pittsburgh, PA, USA) apparatus. High purity hydrogen (purity $99.9995 \%$ ) produced by a hydrogen generator according to the pyrolysis method was used in the experiments. The residual pressure in the vacuum chamber was $10^{-4}$ Pa. Hydrogenation temperature 
was varied from 350 to $450{ }^{\circ} \mathrm{C}$, heating rate was $6^{\circ} \mathrm{C} \cdot \mathrm{min}^{-1}$, hydrogen pressure was kept constant (0.2 MPa).

\subsection{Characterization}

Surface morphology and elemental composition were investigated by scanning electron microscopy (SEM) using Hitachi S-3400N (Tokyo, Japan) equipped with energy-dispersive X-ray spectroscopy (EDX) attachment. For cross-section SEM analysis, the polished samples were chemically etched with a solution of $\mathrm{HNO}_{3}, \mathrm{HF}$ and $\mathrm{H}_{2} \mathrm{O}(45,5$ and 50 vol.\%, respectively).

Phase composition was analyzed by X-ray diffraction in $\theta-2 \theta$ geometry using XRD 7000S diffractometer (Shimadzu, Kyoto, Japan) equipped with high-speed wide-range 1280 channels detector OneSight. The diffraction data was analyzed using Sleve+ program. As a reference for the patterns of $\alpha-\mathrm{Zr}, \gamma-\mathrm{ZrH}$ and $\delta-\mathrm{ZrH}$ there were the ICDD PDF-4+ databases: \#04-004-8479, \#03-0656223 and \#04-002-2839 used, respectively.

Depth distribution of elements was analyzed by glow-discharge optical emission spectroscopy (GDOES) using GD Profiler 2 (Horiba, Kyoto, Japan). Adhesion properties were measured using Micro-Scratch Tester "MST-S-AX-0000" (CSEM, Neuchatel, Switzerland) at the following parameters: $0.01 \mathrm{~N}$ initial load, $5 \mathrm{~N}$ final load, $5 \mathrm{~N} \cdot \mathrm{min}^{-1}$ loading rate, $10 \mathrm{~mm}$ length of the scratches.

\section{Results and Discussion}

\subsection{Morphology and Composition of SiC Coating}

Figure 1 shows cross-section SEM images of SiC-coated zirconium alloy Zr-1Nb. It can be seen that $\mathrm{SiC}$ coating is uniformly deposited on the alloy surface and has dense structure. The coating thickness is approx. $1.5 \mu \mathrm{m}$. According to XRD analysis the coating has amorphous structure. Typical grain structure of the $\mathrm{Zr}-1 \mathrm{Nb}$ alloy consists of non-equiaxed $\alpha$-phase grains having the average size of 2-4 $\mu \mathrm{m}$.

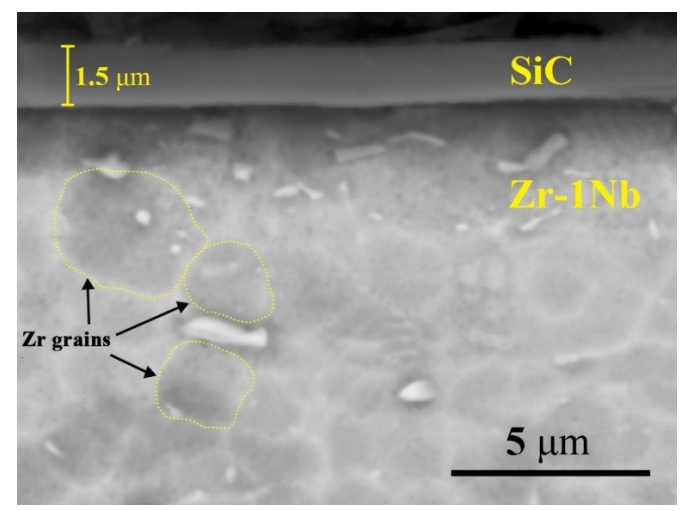

Figure 1. Typical cross-section SEM images of SiC-coated $\mathrm{Zr}-1 \mathrm{Nb}$ alloy.

The energy dispersive $\mathrm{X}$-ray analysis of the deposited coatings shows that $\mathrm{Si} / \mathrm{C}$ ratio in the coating was $47 / 53$. Distribution profiles of elements in the depth are presented in Figure 2 . It is evident that the silicon and carbon are homogeneously distributed over the thickness of the coating. During deposition the C-rich interface between the coating and substrate is formed. The coating thickness is $1.5 \mu \mathrm{m}$, which well correlates with SEM data. Increase of the intensities of $\mathrm{Zr}$ and $\mathrm{Nb}$ lines at the depth higher that $1.4 \mu \mathrm{m}$ is associated with the beginning of substrate sputtering. 


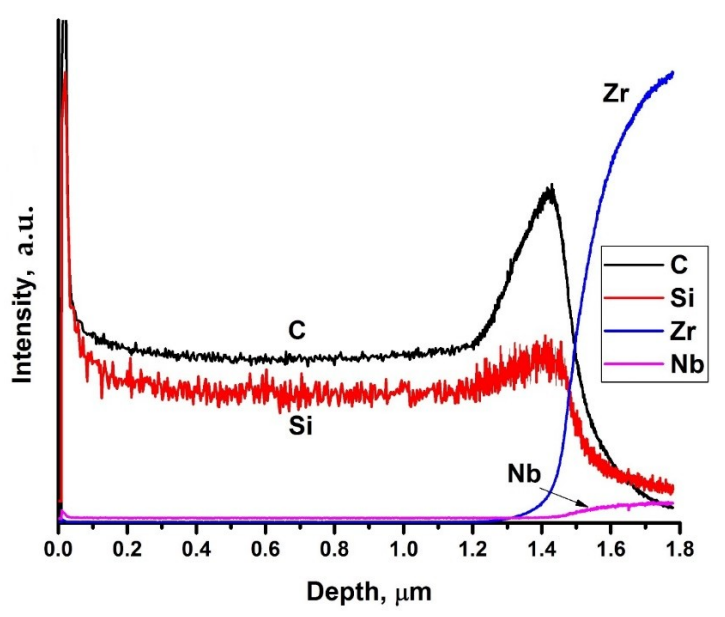

Figure 2. GDOES profiles of elements in SiC-coated $\mathrm{Zr}-1 \mathrm{Nb}$ alloy.

\subsection{Hydrogen Sorption of SiC-Coated Zr-1Nb Alloy}

Figure 3 shows the hydrogen sorption curves of the samples with $\mathrm{SiC}$ coating. The comparison was carried out with the zirconium alloy $\mathrm{Zr}-1 \mathrm{Nb}$ samples without coating, contained native $\mathrm{ZrO}_{2}$ oxide layer on the surface. The $\mathrm{ZrO}_{2}$ layer thickness is typically $15-30 \mathrm{~nm}$. The analysis of the curves showed that hydrogenation proceeds faster in the case of uncoated alloy. The sorption rate at $350{ }^{\circ} \mathrm{C}$ is relatively low compared to the other temperatures investigated; the SiC-coated sample is almost impermeable to hydrogen. It is also seen that increase in temperature leads to increase in the intensity of hydrogen absorption both by uncoated and SiC-coated samples.

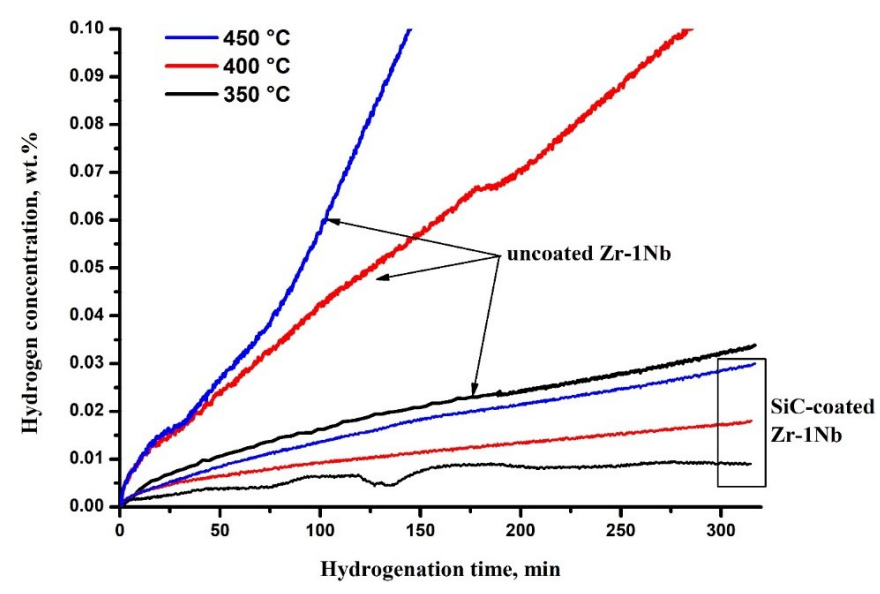

Figure 3. Hydrogen sorption kinetic curves.

To quantify the hydrogenation of the alloy, the average hydrogen sorption rates were calculated from Figure 3 based on the following Equation:

$$
q_{\mathrm{H}}=\frac{C_{\mathrm{H}}}{\Delta t}(\mathrm{wt} . \% / \mathrm{s})
$$

where $C_{\mathrm{H}}$-concentration of absorbed hydrogen, $\Delta t$-hydrogenation time.

To analyze the kinetics of hydrogen sorption, the Arrhenius plots for hydrogen sorption rate were plotted in Figure 4. The linear dependencies in Figure 4 indicate that the hydrogen sorption kinetics of uncoated and $\mathrm{SiC}$-coated alloys meets the Arrhenius law. Hydrogen sorption rate of as-received $\mathrm{Zr}-1 \mathrm{Nb}$ alloy in the indicated temperature range is several times lower than the values obtained in [22]. The lower hydrogen sorption rate by the uncoated alloy is attributed to the formation of $\mathrm{ZrO}_{2}$ barrier layer, which prevents hydrogen penetration [23]. At the temperatures used in the present 
work, the reaction of oxide layer reduction by hydrogen practically does not proceed; only oxygen depletion processes are possible in the $\mathrm{ZrO}_{2}$ oxide layer [24]. At higher temperatures (above $800{ }^{\circ} \mathrm{C}$ ), the influence of oxide layer on hydrogen permeation decreases, its protective properties are lost due to reducing $\mathrm{H}$ environment [25]. It could be seen that $\mathrm{SiC}$ coating reduces hydrogen sorption rate in the investigated temperature range and time span of the experiments. The sorption rate decreases by 8.1 times in comparison with the uncoated alloy at the temperature of $450{ }^{\circ} \mathrm{C}$ mainly due to the low hydrogen permeability of $\mathrm{SiC}$ coatings. The activation energy $\left(E_{\mathrm{a}}\right)$ for hydrogen sorption of SiC-coated $\mathrm{Zr}-1 \mathrm{Nb}$ alloy $\left(44.9 \mathrm{~kJ} \cdot \mathrm{mol}^{-1}\right)$ is lower than that for uncoated alloy $\left(74 \mathrm{~kJ} \cdot \mathrm{mol}^{-1}\right)$. This indicates that in order to activate the sorption process of SiC-coated alloy, it is necessary to expend less energy probably due to the lower activation energy of hydrogen adsorption on the $\mathrm{SiC}$ surface than $\mathrm{ZrO}_{2}$. Although the activation energy is lower for the coated alloy, it has positive effect at the indicated temperature range since the protective properties against hydrogen permeation increase with temperature. In our experiments and in the operating conditions of nuclear reactors, hydrogen has enough energy to penetrate into the $\mathrm{SiC}$ coating or $\mathrm{ZrO}_{2}$; however, due to lower hydrogen diffusion through the $\mathrm{SiC}$ coating hydrogenation of the coated alloy proceeds much slower. Furthermore, extrapolation of the Arrhenius plot to higher temperatures suggests that at higher temperatures the SiC coating will protect the alloy even better (Figure 4).

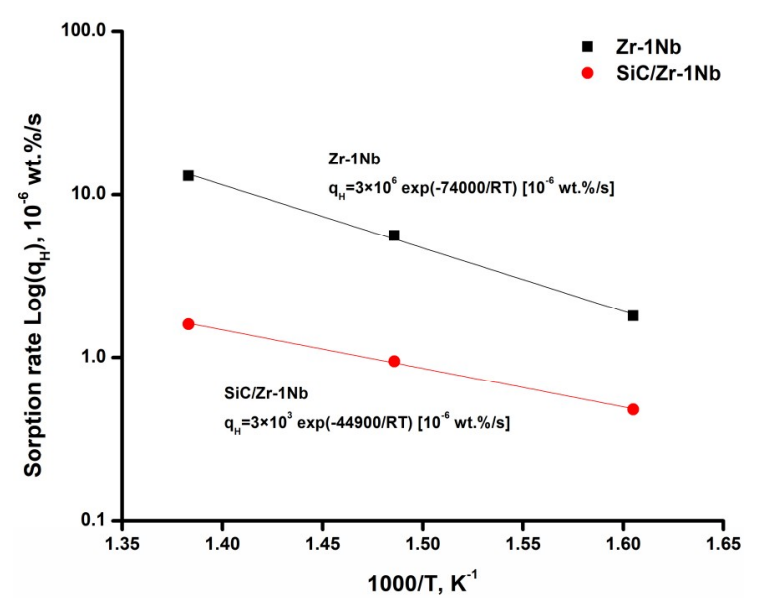

Figure 4. Arrhenius plot for hydrogen sorption tests of $\mathrm{Zr}-1 \mathrm{Nb}$ and $\mathrm{SiC} / \mathrm{Zr}-1 \mathrm{Nb}$ systems.

\subsection{Crystalline Structure of Hydrogenated Samples}

X-ray diffraction analysis was performed to evaluate the structural parameters of hydrogenated samples (Figure 5). Detailed phase composition analysis, lattice parameters and microstrains are demonstrated in Table 2. The as-received zirconium alloy is entirely comprised of the hexagonal close-packed (HCP) $\alpha$-phase with lattice parameters: $a=3.2324, c=5.1472$. Hydrogenation is accompanied by the formation of hydride compounds: cubic $\delta$ zirconium hydride at the temperature of $350{ }^{\circ} \mathrm{C}$; tetragonal $\gamma$ and cubic $\delta$ zirconium hydrides at higher temperatures. There are different opinions about the formation of the metastable $\gamma$ phase of zirconium hydride. On the one hand, it is assumed that $\gamma$ is formed at low concentrations of hydrogen and transforms into $\delta$ hydride [26]. On the other hand, $\gamma$ phase is formed from $\delta$ hydride due to martensitic transformation [27]. Moreover, it was shown that $\gamma$ hydride transforms to $\delta$ hydride in zirconium alloy $\mathrm{Zr}-2.5 \mathrm{Nb}$ at temperatures above $180-200{ }^{\circ} \mathrm{C}$ [28], while for pure zirconium the transition temperature is about $255^{\circ} \mathrm{C}$ [29]. However, there are other works indicating that the formation of $\gamma$ phase occurs at higher temperatures (above $400^{\circ} \mathrm{C}$ ), which is confirmed by in situ X-ray diffraction during gas-phase hydrogenation [30]. In the present work, the $\gamma$ phase is formed after hydrogenation at $400{ }^{\circ} \mathrm{C}$ and higher, and the content of metastable $\gamma$ phase increases with temperature (Table 2). It should be noted that hydrogen concentration in the sample hydrogenated at the temperature of $450{ }^{\circ} \mathrm{C}$ is $0.23 \mathrm{wt}$. \% which is about two times higher than at $400{ }^{\circ} \mathrm{C}$. Thus, increase in the hydrogenation temperature leads to the metastable $\gamma$ 
phase formation, either directly in the hydrogenation process, or as a result of the $\delta \rightarrow \gamma$ transformation during slow cooling to room temperature. The formation of $\gamma-\mathrm{ZrH}$ was also observed during the slow cooling of zirconium hydrides in [31]. In $\mathrm{SiC}$ coated samples, the hydrides formation was observed only during hydrogenation at $450{ }^{\circ} \mathrm{C}$ due to a larger amount of absorbed hydrogen than at lower temperatures. It should also be noted that no metastable phase was detected in these samples. Probably, it should be associated with lower concentration of absorbed hydrogen in comparison with uncoated samples, or to the specificity of hydrogen sorption mechanisms. The latter may be manifested in the difference between the rates of $\mathrm{H}$ permeation and accumulation in cases of uncoated and SiC-coated alloy.
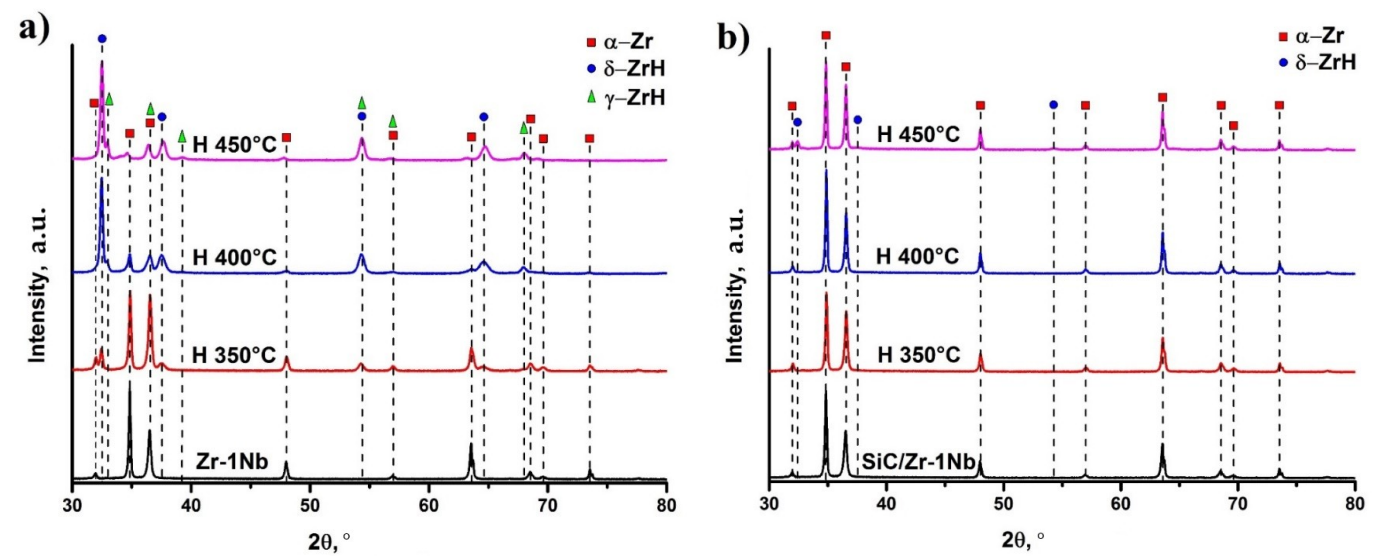

Figure 5. XRD patterns of hydrogenated $\mathrm{Zr}-1 \mathrm{Nb}(\mathbf{a})$ and $\mathrm{SiC}$-coated $\mathrm{Zr}-1 \mathrm{Nb}$ alloy (b).

Table 2. X-ray diffraction results.

\begin{tabular}{|c|c|c|c|c|c|}
\hline Sample & Phases & Content, vol. $\%$ & Lattice Parameters, Å & $c l a$ & $\underset{\times 10^{-3}}{\operatorname{Microstrain}} \Delta d / d$, \\
\hline $\mathrm{SiC} / \mathrm{Zr}-1 \mathrm{Nb}$ & Zr_hcp & 100 & $\begin{array}{l}a=3.2324 \\
c=5.1472\end{array}$ & 1.592 & 0.8 \\
\hline \multirow[t]{2}{*}{ Zr-1Nb_H 350} & Zr_hcp & 79.7 & $\begin{array}{l}a=3.2304 \\
c=5.1452\end{array}$ & 1.593 & 1.2 \\
\hline & ZrH_fcc & 20.3 & $a=4.7786$ & - & 2.9 \\
\hline \multirow{3}{*}{ Zr-1Nb_H 400} & Zr_hcp & 28.3 & $\begin{array}{l}a=3.2268 \\
c=5.1438\end{array}$ & 1.594 & 5.7 \\
\hline & ZrH_fcc & 66.9 & $a=4.7784$ & - & 3.3 \\
\hline & ZrH_fct & 4.8 & $\begin{array}{l}a=4.5873 \\
c=4.9592\end{array}$ & 1.081 & 3.0 \\
\hline \multirow{3}{*}{$\mathrm{Zr}-1 \mathrm{Nb} \_\mathrm{H} 450$} & Zr_hcp & 12.1 & $\begin{array}{l}a=3.2298 \\
c=5.1666\end{array}$ & 1.599 & - \\
\hline & ZrH_fcc & 69.4 & $a=4.7783$ & - & 3.9 \\
\hline & ZrH_fct & 18.5 & $\begin{array}{l}a=4.5832 \\
c=4.9632\end{array}$ & 1.083 & 3.8 \\
\hline SiC/Zr-1Nb_H 350 & Zr_hcp & 100 & $\begin{array}{l}a=3.2329 \\
c=5.1496\end{array}$ & 1.593 & 0.5 \\
\hline $\mathrm{SiC} / \mathrm{Zr}-1 \mathrm{Nb} \_\mathrm{H} 400$ & Zr_hcp & 100 & $\begin{array}{l}a=3.2325 \\
c=5.1497\end{array}$ & 1.593 & 0.7 \\
\hline \multirow[t]{2}{*}{$\mathrm{SiC} / \mathrm{Zr}-1 \mathrm{Nb} \_\mathrm{H} 450$} & Zr_hcp & 85.5 & $\begin{array}{l}a=3.2304 \\
c=5.1482\end{array}$ & 1.594 & 0.8 \\
\hline & $\mathrm{ZrH} \_\mathrm{fcc}$ & 14.5 & $\begin{array}{l}a=3.2304 \\
c=5.1482\end{array}$ & - & 6.4 \\
\hline
\end{tabular}

It is evident that hydrogenation leads to lattice distortion of the zirconium $\alpha$-phase, accompanied by increase in the $c / a$ ratio and increase of microstrains. Increase in the $c / a$ ratio in the uncoated samples is observed with the hydrogenation temperature rising, which is caused by increase in the 
absorbed hydrogen concentration in the samples. In the SiC-coated samples, slight lattice distortion of the $\alpha$ phase and the $\delta$ zirconium hydride formation occur only at the hydrogenation temperature of $450{ }^{\circ} \mathrm{C}$. At lower temperatures, hydrides were not found, which is associated with low hydrogen permeation through the $\mathrm{SiC}$ coating.

\subsection{Depth Distribution of Elements}

Figure 6 shows depth distribution profiles of elements in hydrogenated at $450{ }^{\circ} \mathrm{C}$ uncoated and $\mathrm{SiC}$-coated $\mathrm{Zr}-1 \mathrm{Nb}$ alloys. Hydrogen homogeneously distributed in the surface hydride layer in the as-received sample (see Figure 6a). Probably, this is associated with high hydrogen diffusion rate into zirconium alloy at $450{ }^{\circ} \mathrm{C}$ and low cooling rate $\left(2{ }^{\circ} \mathrm{C} \cdot \mathrm{min}^{-1}\right)$, which leads to hydrogen redistribution. It should be noted that hydrogen has non-homogeneous distribution due to the oxide layer formation on the zirconium surface. Hydrogen has gradient distribution in the SiC-coated sample. Furthermore, hydrogen trapping is observed at the carbon-rich interface between the $\mathrm{SiC}$ coating and the alloy matrix. A small amount of hydrogen penetrates into the alloy depth, which leads to the precipitation of $\delta$ zirconium hydrides.
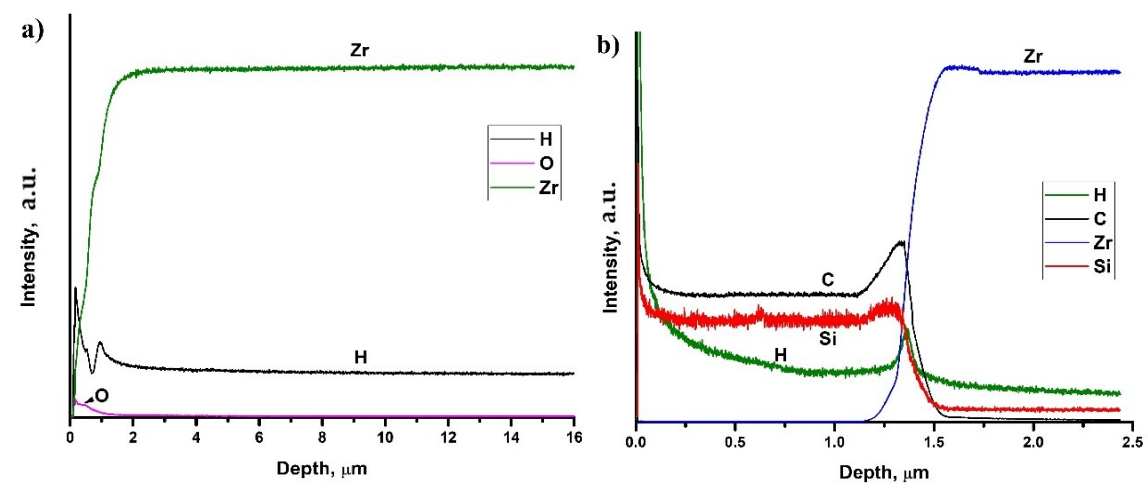

Figure 6. Depth distribution of elements in hydrogenated $\mathrm{Zr}-1 \mathrm{Nb}(\mathbf{a})$ and $\mathrm{SiC}$-coated $\mathrm{Zr}-1 \mathrm{Nb}$ alloy (b).

\subsection{Adhesion of SiC Coating on Zr-1Nb Alloy}

Adhesion properties of $\mathrm{SiC}$ coatings were measured on the samples hydrogenated at highest temperature $\left(450^{\circ} \mathrm{C}\right)$. Figure 7 shows the dependence between friction coefficient and load applied to the indenter. The scratch adhesive tracks are also presented as the inset in Figure 7. The adhesive strength of the deposited coatings before hydrogenation is $5.0 \pm 0.5 \mathrm{~N}$. The adhesion strength after hydrogenation does not change significantly. The friction coefficient of $\mathrm{SiC}$ coating is about 0.25 . Local abrasion of the coating and appearance of cracks occur under the load of $4.1 \mathrm{~N}$ (Lc1). The critical load of coating destruction (Lc2) was $4.6 \mathrm{~N}$. These results indicate good adhesion of the SiC coating and their stability during hydrogenation of the zirconium alloy. However, negative effects (peeling, cracking) during high-temperature oxidation of zirconium alloys with $\mathrm{SiC}$ coating were demonstrated in [14]. On the one hand, this is due to zirconium phase transformations of $\alpha \rightarrow \alpha+\beta \rightarrow \beta$, accompanied by lattice expansion. On the other hand, this can be caused by the difference in the thermal expansion coefficients of the $\beta$-zirconium phase and the $\mathrm{SiC}$ coating. In addition, hydrogenation of the alloy can also have a negative effect on the adhesive properties of the coating, in view of swelling of the zirconium matrix due to precipitation of hydride compounds, which have lower density than metal. The results of this work show that adhesive properties deterioration of $\mathrm{SiC}$ coating during hydrogenation up to $300 \mathrm{ppm}(0.03 \mathrm{wt} . \%)$ does not occur. However, to protect zirconium alloys under high-temperature oxidation, the use of adhesive layers is desirable. Therefore, in the future, it is necessary to perform complex studies of hydrogenation and durability of $\mathrm{SiC}$ coatings with adhesive interlayers under high-temperature oxidation conditions. 


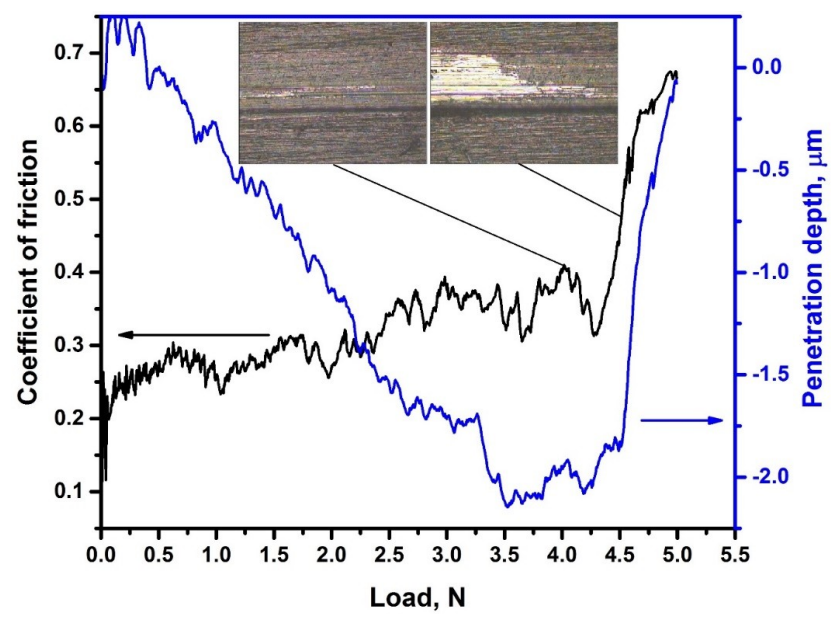

Figure 7. Evolution of coefficient of friction and penetration depth during scratch testing. Insets: scratch tracks at critical loads Lc1 and Lc2.

\section{Conclusions}

Amorphous $\mathrm{SiC}$ coatings with the thickness of $1.5 \mu \mathrm{m}$ were deposited on zirconium alloy $\mathrm{Zr}-1 \mathrm{Nb}$ substrate by DC magnetron sputtering of composite cathode. Hydrogen sorption behavior of $\mathrm{SiC}$-coated $\mathrm{Zr}-1 \mathrm{Nb}$ alloy was investigated during gas-phase hydrogenation in the temperature range of $350-450{ }^{\circ} \mathrm{C}$. It was found that hydrogen sorption by $\mathrm{Zr}-1 \mathrm{Nb}$ alloy significantly decreased due to low hydrogen permeability of the $\mathrm{SiC}$ coating. The hydrogen sorption rate at $450{ }^{\circ} \mathrm{C}$ decreases by approximately 8 times as compared to uncoated alloy with surface oxide layer. At operating temperature of nuclear reactors $\left(\sim 350^{\circ} \mathrm{C}\right)$, the coating is almost impermeable to hydrogen. It was observed that hydrogenation of uncoated alloy leads to hydrides precipitation: cubic $\delta$ hydrides at $350{ }^{\circ} \mathrm{C}$ and $\delta+\gamma$ hydrides at 400 and $450{ }^{\circ} \mathrm{C}$. Only $\delta$ hydrides were detected in the SiC-coated alloy hydrogenated at $450^{\circ} \mathrm{C}$. Hydrogen trapping in the C-rich interface between the SiC coating and alloy substrate was observed. No deterioration of adhesive properties of $\mathrm{SiC}$ coating was observed under hydrogenation up to $450^{\circ} \mathrm{C}$. It could be concluded that deposition of $\mathrm{SiC}$ coating could be efficient way to protect zirconium alloys from hydrogen permeation both at operational and elevated temperatures.

Author Contributions: Conceptualization and Methodology, E.B.K. and M.S.S.; Validation, Investigation and Data Curation, T.L.M., A.V.K., Y.S. and A.O.; Writing-Original Draft Preparation, E.B.K. and A.O.; Supervision, E.B.K.; Project Administration and Funding Acquisition, E.B.K. and M.S.S.

Funding: This study was funded by the governmental program "Science", research project (No. 11.3683.2017/4.6) as well as by Tomsk Polytechnic University Competitiveness Enhancement Program grant.

Acknowledgments: The authors thank Olga S. Tupikova (National Research Tomsk Polytechnic University) for evaluation of adhesion properties.

Conflicts of Interest: The authors declare no conflicts of interest.

\section{References}

1. Zinkle, S.J.; Was, G.S. Materials challenges in nuclear energy. Acta Mater. 2013, 61, 735-758. [CrossRef]

2. Sabol, G. ZIRLO ${ }^{\mathrm{TM}}$ —An Alloy Development Success. J. ASTM Int. 2005, 2, 1-22. [CrossRef]

3. Adamson, R.; Cox, B.; Garzarolli, F.; Strasser, A.; Rudling, P.; Wikmark, G. Corrosion of Zirconium Alloys; Zirat-7 Special Topics Report; Advanced Nuclear Technology International: Uppsala, Sweden, 2002.

4. Suman, S.; Khan, M.K.; Pathak, M. Effects of hydrogen on thermal creep behaviour of Zircaloy fuel cladding. J. Nucl. Mater. 2017, 498, 20-32. [CrossRef]

5. Silva, K.R.F.; dos Santos, D.S.; Ribeiro, A.F.; Almeida, L.H. Hydrogen diffusivity and hydride formation in rich-zirconium alloys used in nuclear reactors. Defect Diffus. Forum 2010, 297, 722-727. [CrossRef]

6. Zieliński, A.; Sobieszczyk, S. Hydrogen-enhanced degradation and oxide effects in zirconium alloys for nuclear applications. Int. J. Hydrog. Energy 2011, 36, 8619-8629. [CrossRef] 
7. Mani Krishna, K.V.; Sain, A.; Samajdar, I.; Dey, G.K.; Srivastava, D.; Neogy, S.; Tewari, R.; Banerjee, S. Resistance to hydride formation in zirconium: An emerging possibility. Acta Mater. 2006, 54, 4665-4675. [CrossRef]

8. Singh, R.; Kishore, R.; Singh, S.; Sinha, T.; Kashyap, B. Stress-reorientation of hydrides and hydride embrittlement of Zr-2.5 wt \% Nb pressure tube alloy. J. Nucl. Mater. 2004, 325, 26-33. [CrossRef]

9. Hui, R.; Cook, W.; Sun, C.; Xie, Y.; Yao, P.; Miles, J.; Olive, R.; Li, J.; Zheng, W.; Zhang, L. Deposition, characterization and performance evaluation of ceramic coatings on metallic substrates for supercritical water-cooled reactors. Surf. Coat. Technol. 2011, 205, 3512-3519. [CrossRef]

10. Barrett, F.; Huang, X.; Guzonas, D. Characterization of $\mathrm{TiO}_{2}$-doped yttria-stabilized zirconia (YSZ) for supercritical water-cooled reactor insulator application. J. Therm. Spray Technol. 2013, 22, 734-743. [CrossRef]

11. Wiklund, U.; Hedenqvist, P.; Hogmark, S.; Stridh, B.; Arbell, M. Multilayer coatings as corrosion protection of Zircaloy. Surf. Coat. Technol. 1996, 86, 530-534. [CrossRef]

12. Khatkhatay, F.; Jiao, L.; Jian, J.; Zhang, W.; Jiao, Z.; Gan, J.; Zhang, H.; Zhang, X.; Wang, H. Superior corrosion resistance properties of TiN-based coatings on Zircaloy tubes in supercritical water. J. Nucl. Mater. 2014, 451, 346-351. [CrossRef]

13. Jin, D.; Yang, F.; Zou, Z.; Gu, L.; Zhao, X.; Guo, F.; Xiao, P. A study of the zirconium alloy protection by $\mathrm{Cr}_{3} \mathrm{C}_{2}-\mathrm{NiCr}$ coating for nuclear reactor application. Surf. Coat. Technol. 2016, 287, 55-60. [CrossRef]

14. Usui, T.; Sawada, A.; Amaya, M.; Suzuki, A.; Chikada, T.; Terai, T. SiC coating as hydrogen permeation reduction and oxidation resistance for nuclear fuel cladding. J. Nucl. Sci. Technol. 2015, 52, 1318-1322. [CrossRef]

15. Younker, I.; Fratoni, M. Neutronic evaluation of coating and cladding materials for accident tolerant fuels. Prog. Nucl. Energy 2016, 88, 10-18. [CrossRef]

16. Lorrette, C.; Sauder, C.; Billaud, P.; Hossepied, C.; Loupias, G.; Braun, J.; Michaux, A. SiC/SiC composite behavior in LWR conditions and under high temperature steam environment. In Proceedings of the Top Fuel 2015, Zurich, Switzerland, 13-17 September 2015; pp. 126-134.

17. Terrani, K.A.; Pint, B.A.; Parish, C.M.; Silva, C.M.; Snead, L.L.; Katoh, Y. Silicon carbide oxidation in steam up to $2 \mathrm{MPa}$. J. Am. Ceram. Soc. 2014, 97, 2331-2352. [CrossRef]

18. Lei, Y.; Yu, Y.; Ren, C.; Zou, S.; Chen, D.; Wong, S.; Wilson, I. Compositional and structural studies of DC magnetron sputtered SiC films on Si(111). Thin Solid Films 2000, 365, 53-57. [CrossRef]

19. Sigl, L.S. Thermal conductivity of liquid phase sintered silicon carbide. J. Eur. Ceram. Soc. 2003, 23, 1115-1122. [CrossRef]

20. Bao, W.; Xue, J.; Liu, J.-X.; Wang, X.; Gu, Y.; Xu, F.; Zhang, G.-J. Coating SiC on Zircaloy-4 by magnetron sputtering at room temperature. J. Alloy. Compd. 2018, 730, 81-87. [CrossRef]

21. Al-Olayyan, Y.; Fuchs, G.E.; Baney, R.; Tulenko, J. The effect of Zircaloy-4 substrate surface condition on the adhesion strength and corrosion of SiC coatings. J. Nucl. Mater. 2005, 346, 109-119. [CrossRef]

22. Kudiiarov, V.; Babikhina, M.; Pushilina, N.; Kashkarov, E.; Syrtanov, M. Influence of surface state on hydrogen sorption by zirconium alloy Zr1Nb. AIP Conf. Proc. 2016, 1772, 030019.

23. Evsin, A.E.; Begrambekov, L.B.; Gumarov, A.I.; Kaplevsky, A.S.; Luchkin, A.G.; Tagirov, L.R.; Vakhitov, I.R. Trapping and desorption of hydrogen isotopes under irradiation of zirconium by deuterium atoms of thermal energies. Vacuum 2016, 129, 183-187. [CrossRef]

24. Evsin, A.E.; Begrambekov, L.B.; Gumarov, A.I.; Kashapov, N.F.; Luchkin, A.G.; Vakhitov, I.R.; Yanilkin, I.V.; Tagirov, L.R. Effect of irradiation by argon ions on hydrogen transport through the surface oxide layer of zirconium. J. Phys. Conf. Ser. 2016, 748, 012011. [CrossRef]

25. Eder, D.; Kramer, R. The stoichiometry of hydrogen reduced zirconia and its influence on catalytic activity. Phys. Chem. Chem. Phys. 2002, 4, 795-801. [CrossRef]

26. Tulk, E.; Kerr, M.; Daymond, M.R. Study on the effects of matrix yield strength on hydride phase stability in Zircaloy-2 and Zr 2.5 wt \% Nb. J. Nucl. Mater. 2012, 425, 93-104. [CrossRef]

27. Zuzek, E.; Abriata, J.P.; San-Martin, A.; Manchester, F.D. The H-Zr (hydrogen-zirconium) system. Bull. Alloy Phase Diagr. 1990, 11, 385-395. [CrossRef]

28. Root, J.H.; Fong, R.W.L. Neutron diffraction study of the precipitation and dissolution of hydrides in Zr-2.5Nb pressure tube material. J. Nucl. Mater. 1996, 232, 75-85. [CrossRef]

29. Mishra, S.; Sivaramakrishnan, K.S.; Asundi, M.K. Formation of the gamma phase by a peritectoid reaction in the zirconium-hydrogen system. J. Nucl. Mater. 1972, 45, 235-244. [CrossRef] 
30. Laptev, R.S.; Syrtanov, M.S.; Kudiiarov, V.N.; Shmakov, A.N.; Vinokurov, Z.S.; Mikhaylov, A.A.; Zolotarev, K.V. In situ investigation of thermo-stimulated decay of hydrides of titanium and zirconium by means of $X$-ray diffraction of synchrotron radiation. Phys. Procedia 2016, 84, 337-341. [CrossRef]

31. Root, J.H.; Small, W.M.; Khatamian, D.; Woo, O.T. Kinetics of the $\delta$ to $\gamma$ zirconium hydride transformation in Zr-2.5Nb. Acta Mater. 2003, 51, 2041-2053. [CrossRef] 